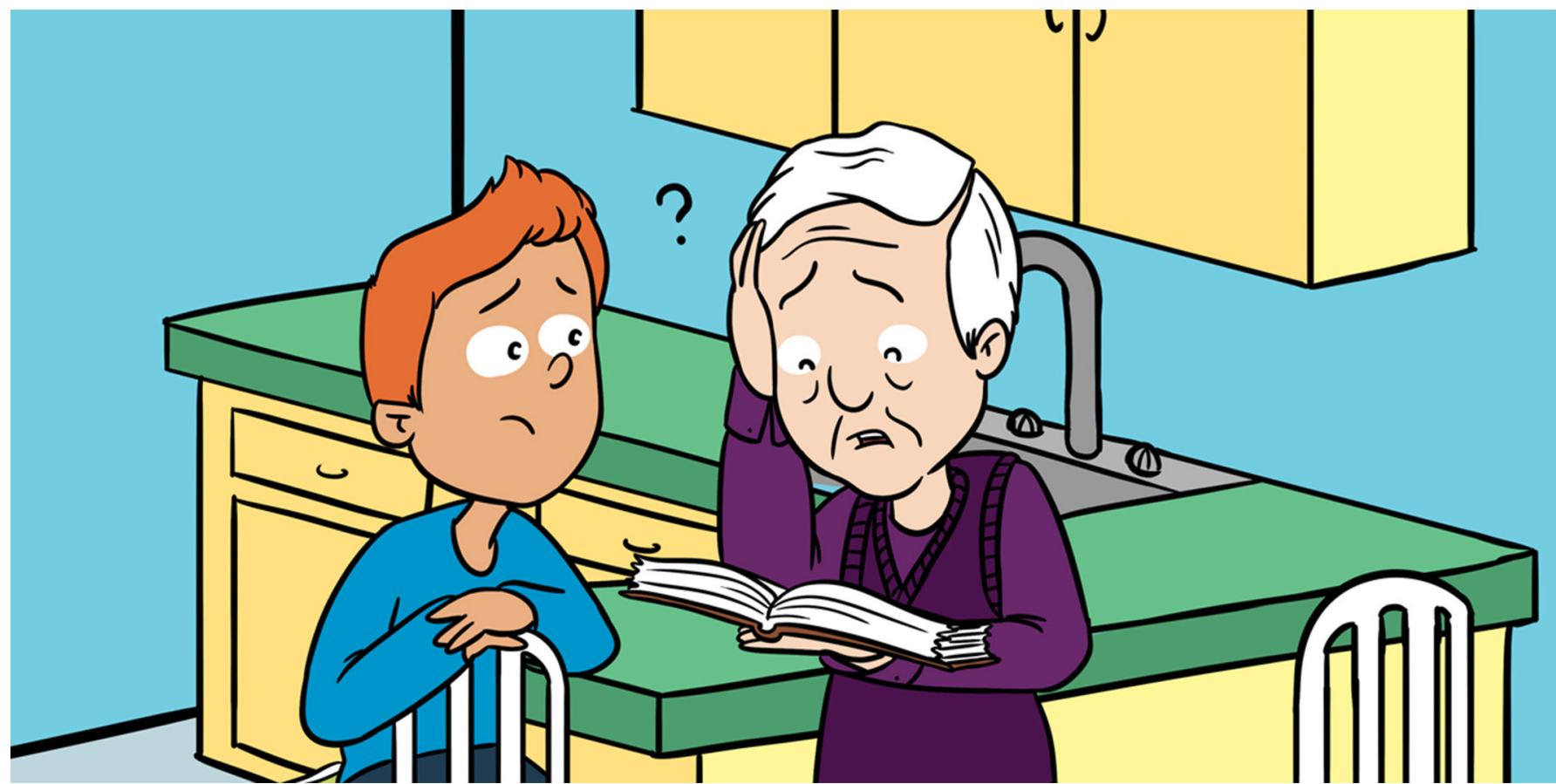

\title{
WHAT ARE NEURODEGENERATIVE DISEASES AND HOW DO THEY AFFECT THE BRAIN?
}

\section{Taryn Berman and Armin Bayati*}

University of Victoria, Victoria, BC, Canada

YOUNG REVIEWERS:

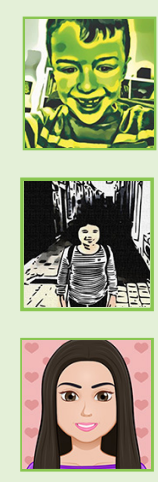

AIDAN

AGE: 8

DANIELA

AGE: 9

ERICA

AGE: 10

LEIMINA

AGE: 10

LUCIE

AGE: 10
How does the brain control movement? What sort of problems occur when the brain is sick? Neurodegenerative disorders are illnesses that involve the death of certain parts of the brain. They are, by far, some of the toughest diseases to cure with debilitating outcomes. Parkinson's and Huntington's Disease are among the most severe and common movement disorders. Although a lot of information has been found about how and why these diseases occur, neurodegenerative disorders remain highly mysterious and complex. This article provides a simpler explanation to allow more people to learn about these diseases.

The brain is an extremely complex organ with vast numbers of pathways that allow us to do the amazing things that we do. The brain is made up of billions of cells that we depend on every second of every day for proper functioning. Some of the most important cells in the brain are 


\section{NEURONS}

Cells that form the brain and communicate with each other so that we can talk, think, move, and accomplish everything else that we do.

NEURODEGENERATIVE DISEASES

Brain illness that causes neurons to die and the brain to shrink.

\section{PARKINSON'S}

\section{DISEASE}

A neurodegenerative disease whose main symptoms are related to problems with movement, due to neuron death in the substantia nigra.

\section{SUBSTANTIA NIGRA}

A brain area that communicates with the basal ganglia so that we can move.

\section{BASAL GANGLIA}

Group of neurons that make up the main brain area needed to control movement. called neurons. Neurons communicate with each other to perform every function of the brain, whether it involves moving around, thinking about topics learned in school, talking to friends, or remembering the list of things we want to buy from the grocery store. Because of the brain's complexity, brain disorders can arise from very small miscommunications between cells.

The cells of the brain are closely connected and miscommunications in one area can disrupt other brain activities, meaning that brain disorders can result in widespread problems. Although there are many diseases and illnesses that can affect the brain, the most complicated of these diseases are called neurodegenerative diseases.

Neurodegenerative diseases result in neuron death. The word neurodegenerative can be split into neuro, meaning brain, and degenerative, meaning breaking down, or dying. Neurodegenerative diseases are a great example of the devastating effects of miscommunications between brain cells. These diseases can influence an individual's movement, speech, memory, intelligence, and much more [1, 2]. Because neurodegenerative diseases are so complex, the cause of many of these diseases remains a mystery.

There are many well-known types of neurodegenerative diseases that originate in different areas of the brain. You may have heard of some of these diseases. The rest of this paper will explore a few neurodegenerative diseases and what effects they have on the people that suffer from them.

\section{PARKINSON'S DISEASE}

Parkinson's Disease is one type of neurodegenerative disease. When neurons die in a part of the brain called the substantia nigra, movement problems appear (Figure 1). The substantia nigra (Latin for "black substance") is a region within the brain that contains a large number of neurons that release a substance called dopamine. By releasing dopamine, the neurons of the substantia nigra communicate with movement-producing parts of the brain, like the frontal lobe and the basal ganglia. The word ganglia means clusters of neurons. The basal ganglia are located deep in the center of the brain and are made up of several different groups of neurons. Neuronal death in the substantia nigra means that these groups of neurons can no longer work properly, causing stumbling and shaking in the people that have this disease [3]. These individuals also experience problems starting and maintaining their movements. 
Figure 1

Side view of the brain, sliced in half, showing the basal ganglia (red), and the substantia nigra (black).

\section{HUNTINGTON'S \\ DISEASE}

A neurodegenerative disease that can be passed on from parent to child and affects the basal ganglia, leading to problems with moving too much.

\section{GENETIC}

Able to be passed on from parent to child.

\section{ALZHEIMER'S}

DISEASE AND LEWY BODY DEMENTIA

Neurodegenerative diseases that mainly lead to memory problems.

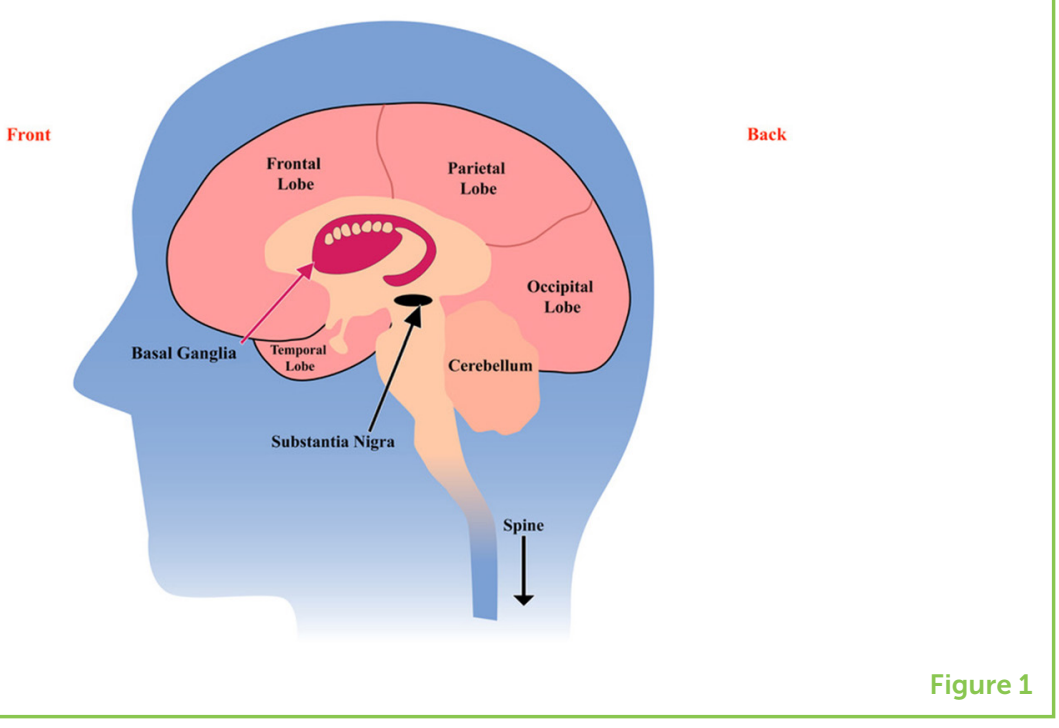

\section{HUNTINGTON'S DISEASE}

Like Parkinson's Disease, Huntington's Disease is also a neurodegenerative disease that causes movement problems and affects the basal ganglia. Unlike Parkinson's Disease, Huntington's Disease is a genetic illness. This means that if either parent has the disease, the children are also very likely to have the illness. Huntington's Disease is a result of abnormal protein buildup in brain, which results in neuronal death, causing the movement disorder. Mainly, individuals with this disease will show excessive movement, movement that is generally unwanted and unnecessary. For example, they often have constant vibrating limbs, something that is out of their control. As the disease progresses, people with Huntington's will find it increasingly hard to move the way they want to move.

In any neurodegenerative disease, if neurons are dying, then the brain is getting smaller! This is a serious problem and causes the person to have memory and thinking problems. These problems are a common feature of all neurodegenerative diseases [2].

\section{DEMENTIA}

Memories are stored in the brain. Although the specific way in which memories are stored is unknown, neurons are definitely responsible for the storage process. We know this, because diseases that cause the death of neurons also cause memory loss. Dementia is a general term for memory loss. Two common types of dementia are Alzheimer's Disease and Lewy body dementia. Every type of dementia is a result of neurodegeneration (shrinking of the brain). Shrinking is caused by a 
lot of neuronal death occurring throughout the brain. Because of the large number of neurons dying, people with dementia not only start losing their memories, but they eventually lose their ability to move, communicate, and even think properly [4].

\section{HOW CAN WE CURE NEURODEGENERATIVE DISEASES?}

The neurodegenerative diseases we have talked about are among the worst kinds of illness any person could possibly have. One reason for this is because we still have no idea how to cure people with neurodegenerative diseases. Researchers and scientists around the world are currently working hard to discover a way to help people with these illnesses. No cure has been found yet, but scientists have come up with a few ideas that have a lot of potential. One of the most exciting ideas that scientists are currently working on is to replace the dead neurons in the brain with new ones [5]. Replacing dead neurons can be done

\section{STEM CELLS}

Immature cells that can become any type of cell in the body, even neurons. using a special type of cell called stem cells. Stem cells are immature cells that can become any type of cell in the body, which is why they can act as a replacement for dead neurons in the brain. Everyone has a small number of stem cells in their body, but these cells are not always working to replace cells that have recently died. Scientists have found that the best way to make stem cells replace dead neurons in the brain is to take stem cells from a person, make them multiply in test tubes in the laboratory, and then put the cells back into the person where they are needed. This idea has even been tried on laboratory animals, like mice, and it worked [5]! Due to the differences between humans and other animals, scientists think that these types of experiments are too risky to be done on people with neurodegenerative diseases. This is why scientists all around the world are working to develop a safer, less risky, way of replacing neurons in the brain with stem cells. When the stem cells are put into the brain, these cells need the proper support structures to attach to and grow. These structures are called scaffolds. Building scaffolds that can support the growth of stem cells within the brain and getting these scaffolds into the brain is one of the great challenges that neuroscientists currently face. However, stem cell treatment for neurodegenerative diseases holds a lot of promise and hopefully, with some more hard work, scientists will find a way to use this treatment to help humans suffering from these diseases.

\section{CONCLUSION}

People all over the world are suffering from neurodegenerative diseases, which are illnesses that lead to cell death in the brain. Some neurodegenerative diseases, like Parkinson's Disease and Huntington's Disease, 
affect the basal ganglia and lead to movement difficulties. Other diseases cause more widespread cell death and lead to memory loss, which is seen in Alzheimer's Disease and Lewy body dementia. There are also rarer types of neurodegenerative diseases that were not covered in this article. Neurodegenerative diseases are horrible illnesses to have, and there is currently no cure; however, researchers around the world are looking into ways to help people with these diseases. One of the most exciting treatments uses stem cells to replace the neurons that have died. With so many brilliant minds working on a cure, hopefully there will soon be help for people with these diseases!

\section{REFERENCES}

1. Bak, T. H., and Chandran, S. 2012. What wires together dies together: verbs, actions and neurodegeneration in motor neuron disease. Cortex 48:936-44. doi: 10.1016/j.cortex.2011.07.008

2. Finkbeiner, S. 2011. Huntington's disease. Cold Spring Harb. Perspect. in Biol. 3:1-24. doi: 10.1101/cshperspect.a007476

3. Kalia, L. V., and Lang, A. E. 2015. Parkinson's disease. Lancet 386:896-912. doi: 10.1016/S0140-6736(14)61393-3

4. Holmes, C., and Amin, J. 2016. Dementia. Medicine (Baltimore) 44:687-90. doi: 10.1016/j.mpmed.2016.08.006

5. Jaiswal, M. 2017. Therapeutic opportunities and challenges of induced pluripotent stem cells-derived motor neurons for treatment of amyotrophic lateral sclerosis and motor neuron disease. Neural. Regen. Res. 12:723-36. doi: $10.4103 / 1673-5374.206635$

SUBMITTED: 12 December 2017; ACCEPTED: 22 November 2018; PUBLISHED ONLINE: 12 December 2018.

EDITED BY: Shekher Mohan, Manchester University, United States

CITATION: Berman T and Bayati A (2018) What Are Neurodegenerative Diseases and How Do They Affect the Brain? Front. Young Minds 6:70. doi: 10.3389/frym.2018.00070

CONFLICT OF INTEREST STATEMENT: The authors declare that the research was conducted in the absence of any commercial or financial relationships that could be construed as a potential conflict of interest.

COPYRIGHT @ 2018 Berman and Bayati. This is an open-access article distributed under the terms of the Creative Commons Attribution License (CC BY). The use, distribution or reproduction in other forums is permitted, provided the original author(s) and the copyright owner(s) are credited and that the original publication in this journal is cited, in accordance with accepted academic practice. No use, distribution or reproduction is permitted which does not comply with these terms. 


\section{YOUNG REVIEWERS}

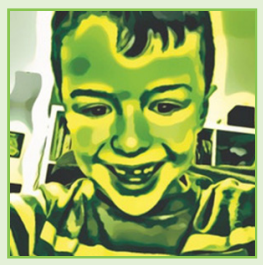

\section{AIDAN, AGE: 8}

I am 8 years old, I like Coding and Science. I like to read a lot as well. I like to read book series like "Wings of Fire," "How to Train Your Dragon," "The Three Doors Trilogy," "Deltora Quest," "His Dark Materials Trilogy," "Mr. Gum," "Harry Potter,"' and "Weir Do."

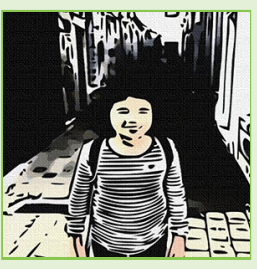

\section{DANIELA, AGE: 9}

$\mathrm{Hi}$, my name is Daniela. I am 9 years old. I live in Australia. My favorite hobby is to play tennis, and my favorite subject is Science. When I grow up I would like to study science and be a doctor.
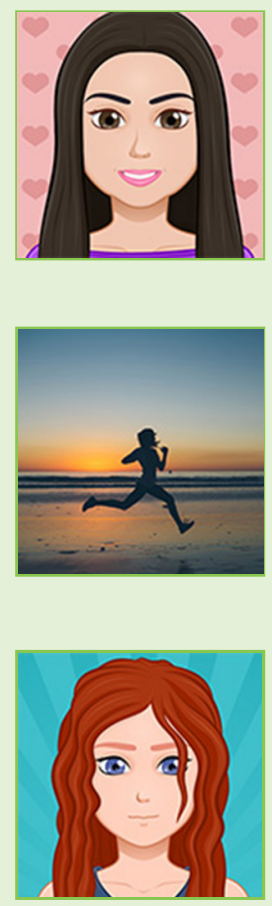

\section{LUCIE, AGE: 10}

I love Science and Maths. I am quite interested in Biology and Chemistry. In my spare time, I like to read. My favorite book genres are non-fiction, action, fantasy, and romance.

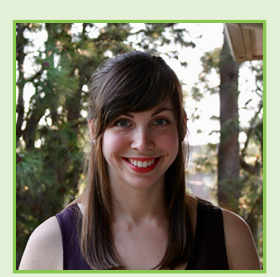

\section{AUTHORS}

\section{TARYN BERMAN}

I am a researcher in the Theoretical and Applied Neuroscience Laboratory at the University of Victoria. My research focuses on personality, decision making, and brain waves. I write papers, volunteer, and bake cookies in my spare time.

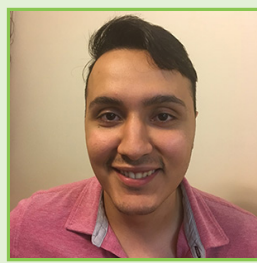

\section{ARMIN BAYATI}

I am currently a researcher at the University of Victoria. My research focuses on neuroscience and human behavior. My favorite thing is to explore the structure of cells using different types of microscopes. In my spare time, I focus on making my research more accessible for other scientists and students by writing about my research and findings. *arminbay@uvic.ca 